\title{
Viable Solution for Next Generation Passive Optical Network 2 (NG-PON 2) Supporting 40Gbps Downstream DQPSK and 10Gbps Upstream OOK
}

\author{
${ }^{1}$ Areez Khalil Memon, ${ }^{2}$ Ahmed Muddassir Khan, ${ }^{3}$ Syed Hyder Abbas Musavi and \\ ${ }^{4}$ Anwar Ali Gaho \\ ${ }^{1234}$ FEST, Indus University, Karachi, Pakistan \\ areez.memon@indus.edu.pk,ahmed.muddassir@indus.edu.pk, \\ dean@indus.edu.pk,anwar.a.gaho@gmail.com
}

\begin{abstract}
This paper demonstrates a simple and viable solution for high data rates challenge in access network by supporting 40Gbps in the downstream with Differential Quadrature Phase Shift Keying (DQPSK) and 10Gbps in the upstream with ON-OFF Keying (OOK) modulated signal. Channel dispersion is compensated by using fiber Bragg grating (FBG) dispersion compensation. The proposed system is analyzed through optisys software with standard values and recommendations of Next Generation Passive Optical Network 2 (NG-PON 2) for high data rate. Transmission performance of the proposed system has been investigated and simulation results shows the BER and power of downstream and upstream are quite better as the power at standard receiver sensitivity BER i.e. 1x10-9 is $32.5 \mathrm{~dB}$ at downstream and $-42.5 \mathrm{~dB}$ at upstream.
\end{abstract}

Keywords: Differential Quadrature Phase Shift Keying (DQPSK), ON-OFF Keying (OOK), fiber Bragg grating (FBG), Next Generation Passive Optical Network-2 (NGPON-2), Bit Error Rate (BER), High data rate

\section{Introduction}

Advancement in Optical access network is necessary to deal with the increasing demand of high data rate. At present, Passive optical networks are deployed at 10Gbps data rate for the consumers with voice and multimedia services simultaneously [1-2]. It is essential to increase the data rate up to 40Gbps which cope up the demands of consumers and viable as next generation passive optical network (NG-PON 2) [3-5]. In order to increase the data rates of passive optical networks, advanced modulation formats have been proposed and implemented to decrease the effect of non-linearity's and dispersion effects [6]. Several modulation formats have been proposed by researchers in downstream and upstream such as NRZ, RZ, MD-RZ [7], CSRZ, MDRZ, DPSK [8], RZDQPSK/OOK [9], Differential Phase Shift Keying (DPSK)/OOK [9], Carrier suppressed return to zero CSRZ-DQPSK/OOK [9-11], NRZ-DQPSK/ASK [12, 13], DPSK/ IRZ $[14,15]$. But either above modulation techniques has been implemented over 10Gbps only (i.e. very low data rate) or proposed techniques have been implemented at very short fiber length, high cost, design complexity and high energy consumption. In this paper, we proposed an architecture which is 40Gbps DQPSK modulation in downstream and $10 \mathrm{Gbps}$ OOK modulation in upstream having fiber length of $10 \mathrm{Km}$ at both streams using FBG dispersion compensation. FBG dispersion compensation is used as it is simple, has low insertion loss and no nonlinearity and ability to provide tunable dispersion compensation compared to other dispersion compensation [16-18]. Important parameters of FBG are reflection coefficient $\left(r_{g}\right)$, phase $\left(\phi_{g}\right)$ and bandwidth whose equations are given below [19] : 


$$
\begin{gathered}
r_{g}=\frac{A_{b}(0)}{A_{f}(0)}=\frac{i k_{g} \sin \left(q_{g} L_{g}\right)}{q_{g} \cos \left(q_{g} L_{g}\right)-i \delta \sin \left(q_{g} L_{g}\right)} \\
\phi_{g}=-\arctan \left[\frac{\operatorname{Im}\left(r_{g}\right)}{\operatorname{Re}\left(r_{g}\right)}\right] \\
\Delta \lambda=\frac{2 \lambda_{B}^{2}}{2 \grave{\mathrm{n}} L_{g} \pi} \sqrt{\left(K_{g} L_{g}\right)^{2}+(\pi)^{2}}
\end{gathered}
$$

Where $A_{b}$ and $A_{f}$ are spectral amplitudes, $\delta$ is the detuning, $K g$ is the coupling coefficient, $q_{g}^{2}=\delta^{2}-k_{g}^{2}$ and $L g$ is the FBG length. Proposed system is fulfilling the requirement of NG-PON 2 in terms of high data rate.

\section{Description of Simulation}

Simulation results have been carried out of high data rate NG-PON. Figure 1 shows the simulated model of high data rate NG-PON having Optical line terminal (OLT), Optical network unit (ONU) and optical fiber having 10Km length between OLT and ONU. CW LASER is used as a carrier source having launch power $=0 \mathrm{dBm}(1 \mathrm{Watt})$ works at $1550 \mathrm{~nm}$, Electrical data stream is generated from pseudo random generator (PRBS) having data rate $40 \mathrm{Gbps}$ which is precoded differentially and modulated with optical carrier signal through two Lithium Niobate Mach-Zehnder modulator (LiNb MZM) which are connected in series as shown in Figure 2. Modulated signal transmitted through optical fiber having attenuation co-efficient of fiber is $0.2 \mathrm{~dB} / \mathrm{km}$ as shown Table 1 . FBG dispersion compensation is used after the signal is transmitted from $10 \mathrm{~km}$ span of optical fiber to eliminate the effect of dispersion and nonlinearities in fiber before demodulation.

Received signal comprises in-phase (I) and quadrature-phase (Q) of DQPSK modulated signal, which are separately extracted from PIN detector circuit after processed through $+45^{\circ}$ and $-45^{\circ}$ phase shifter circuit as shown in Figure 3. For the efficient design, centralized LASER source technique is employed for re-modulation and the received downstream signal is used as an optical carrier of same wavelength and re-modulates the upstream at 10Gbps OOK modulated electrical data as shown in Figure 4.

Table 1. Simulated Model Parameters

\begin{tabular}{|c|c|c|}
\hline \multirow{2}{*}{$\begin{array}{c}\text { Transmission } \\
\text { Section }\end{array}$} & Parameter & Values \\
\hline \multirow{4}{*}{ Fiber } & Frequency of Laser & $193.1 \mathrm{THz}$ \\
\cline { 2 - 3 } & Fiber Length & $10 \mathrm{Km}$ \\
\cline { 2 - 3 } & Dispersion slop & $\begin{array}{c}0.075 \\
\mathrm{ps} / \mathrm{nm}^{2} / \mathrm{km}\end{array}$ \\
\cline { 2 - 3 } & Effective core area & $80 \mathrm{um}^{2}$ \\
\cline { 2 - 3 } & $\begin{array}{c}\text { Non Linear index- } \\
\text { coefficient }\end{array}$ & $2.6 \times 10^{-20}$ \\
\cline { 2 - 3 } & Attenuation Coeff: & $0.2 \mathrm{~dB} / \mathrm{km}$ \\
\cline { 2 - 3 } & $\begin{array}{c}16.75 \\
\mathrm{ps} / \mathrm{nm} / \mathrm{km}\end{array}$ \\
\hline $\begin{array}{c}\text { Receiver } \\
\text { Section }\end{array}$ & $\begin{array}{c}\text { Filter Cutoff } \\
\text { Frequency }\end{array}$ & $\begin{array}{c}0.75^{*} \mathrm{bit} \mathrm{rate} \\
\mathrm{Hz}\end{array}$ \\
\hline
\end{tabular}




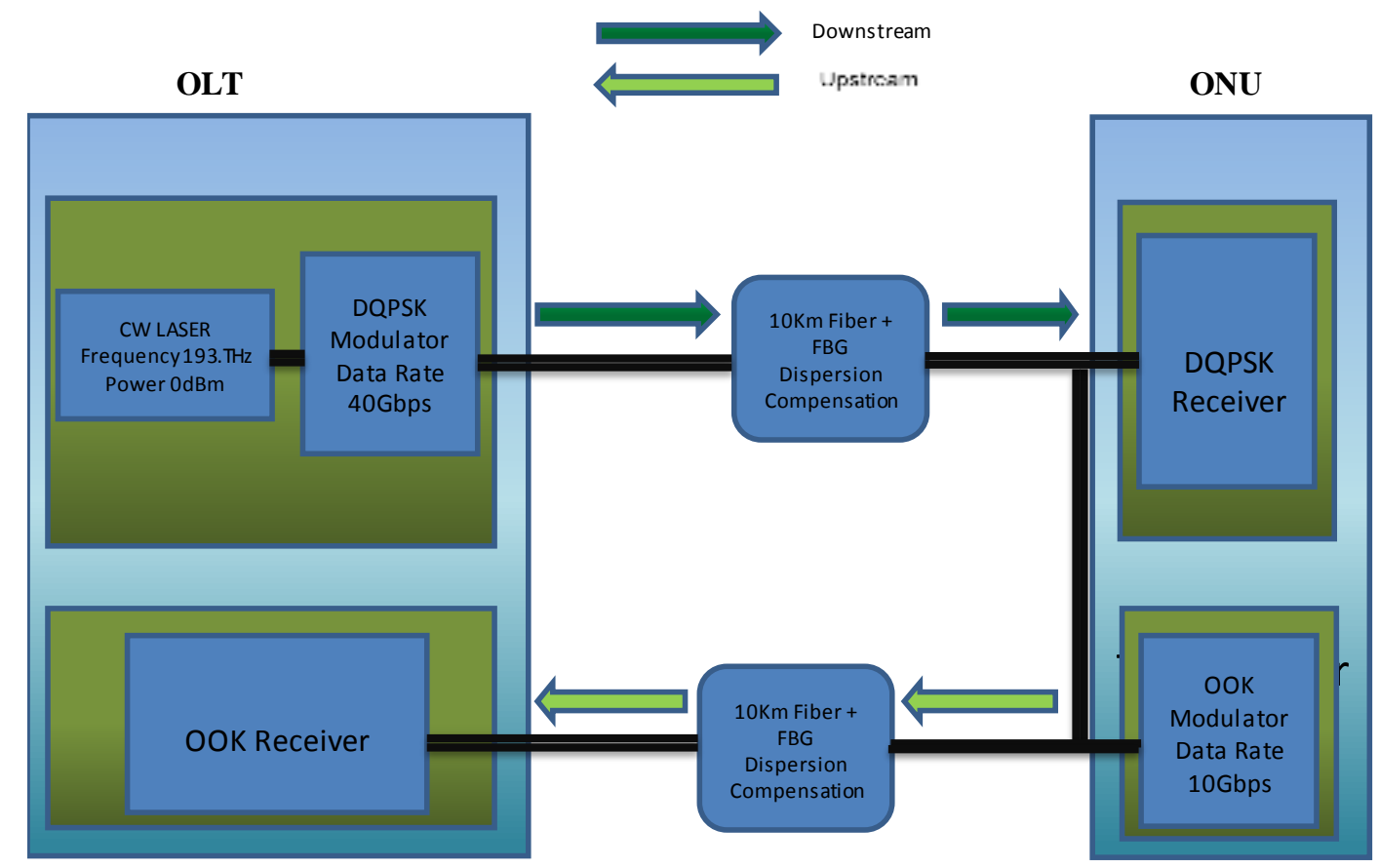

Figure 1. 40Gbps Next Generation Passive Optical Network (NG-PON) with FBG

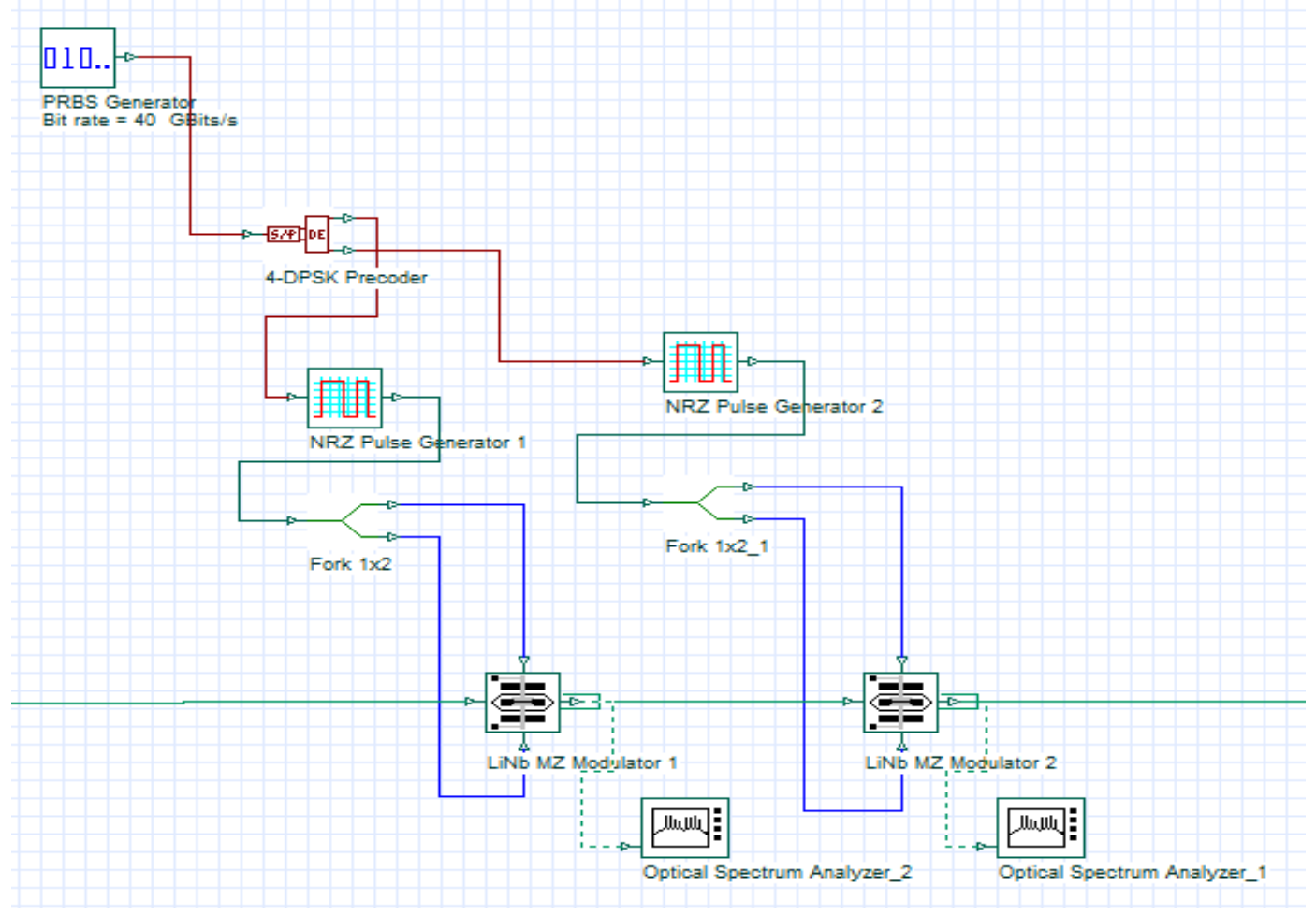

Figure 2. DQPSK Modulator Data Rate 40Gbps 


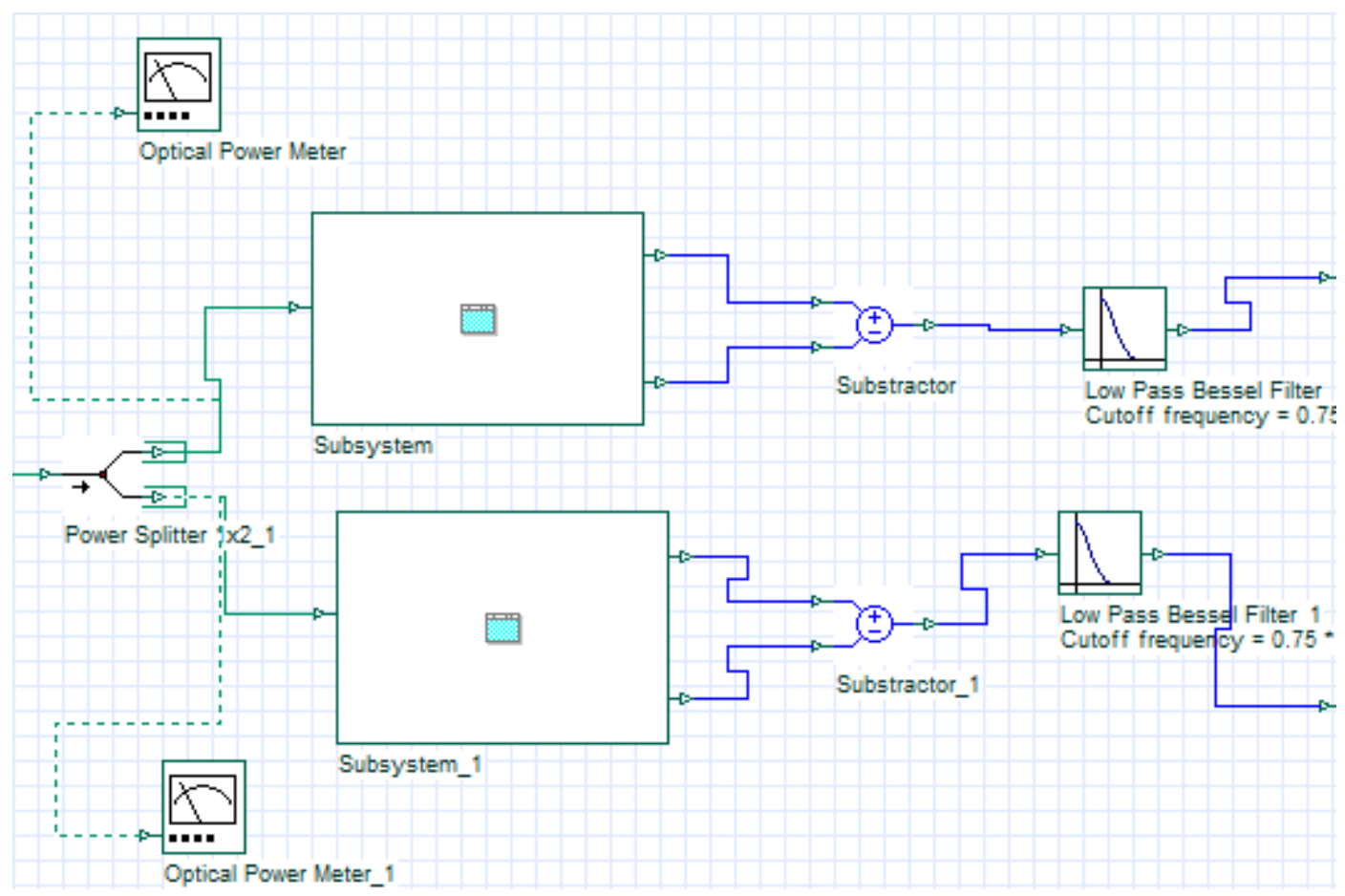

Figure 3. DQPSK Receiver

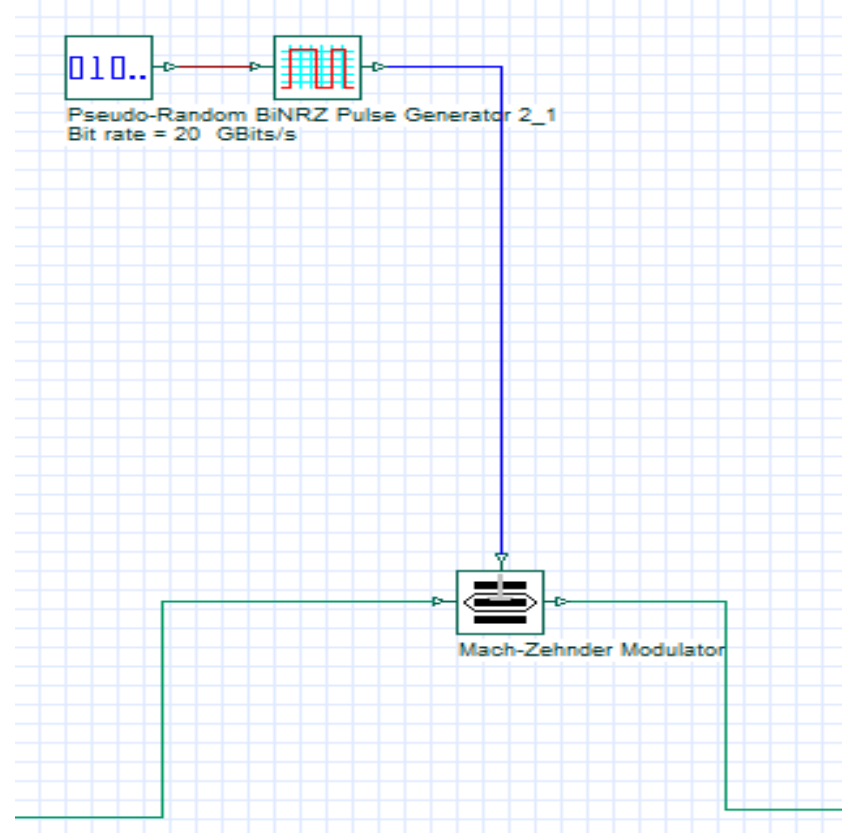

Figure 4. OOK Modulator Data Rate 10Gbps 


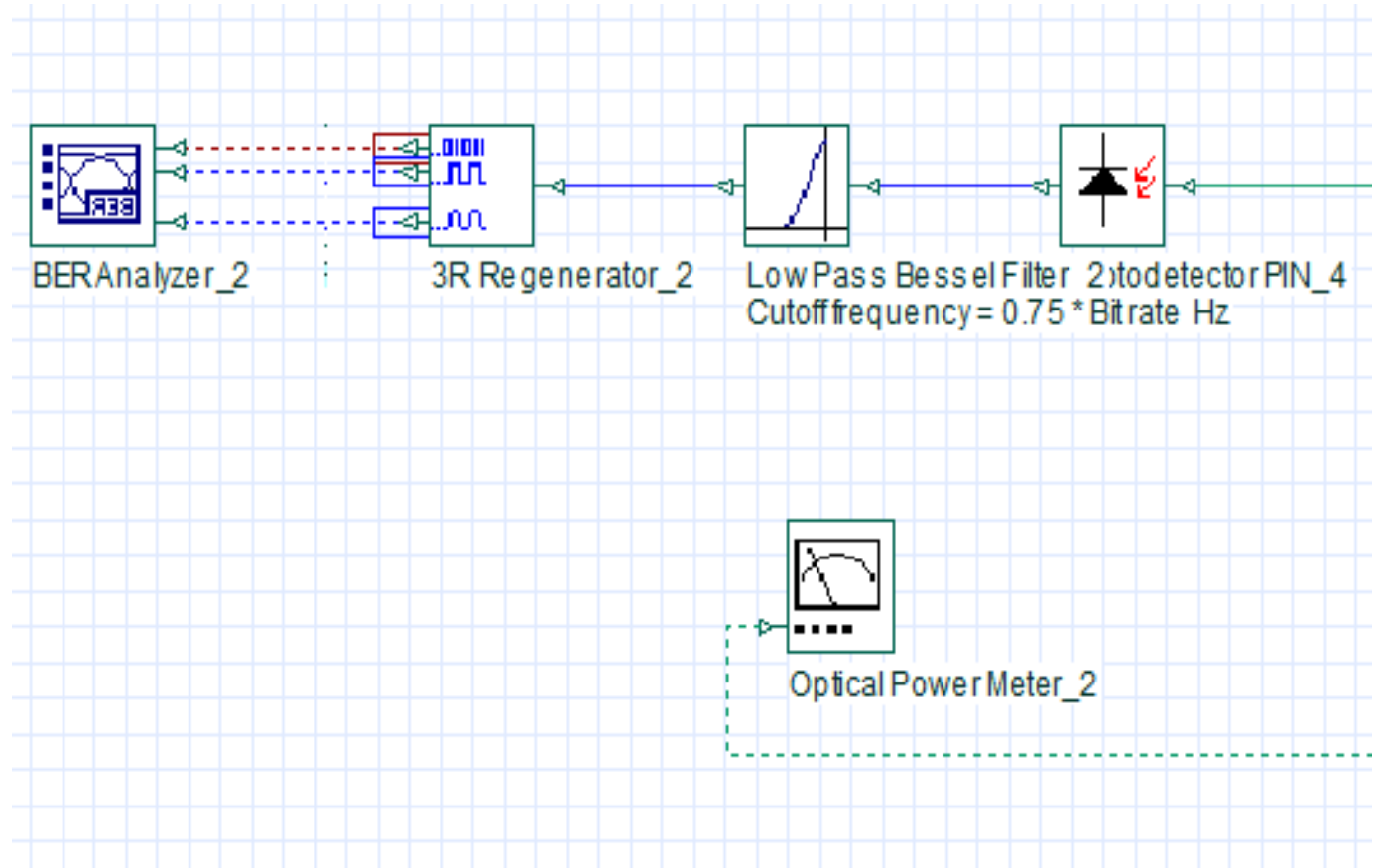

Figure 5. OOK Receiver

Then upstream data from ONU is transmitted back towards OLT through optical fiber length of $10 \mathrm{~km}$ and Ideal dispersion compensation FBG then detected single Photo detector is used as a OOK modulated upstream as a receiver at OLT as shown in Figure 5.

\section{Discussion of Results}

Figure 6 and 7 shows the optical spectrum of DQPSK (downstream) and OOK (upstream) at carrier frequency of $193.1 \mathrm{THz}$ (1550nm wavelength).

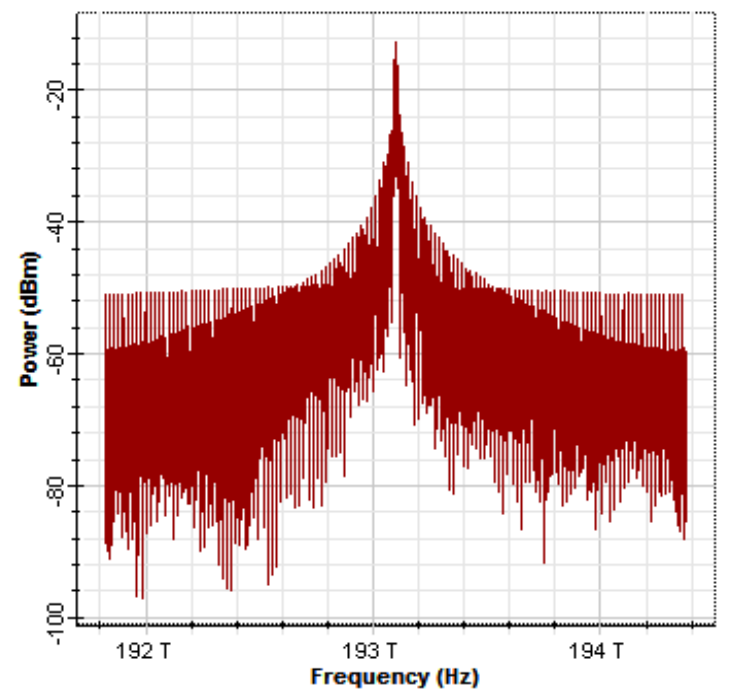

Figure 6. Optical Spectrum of DQPSK 


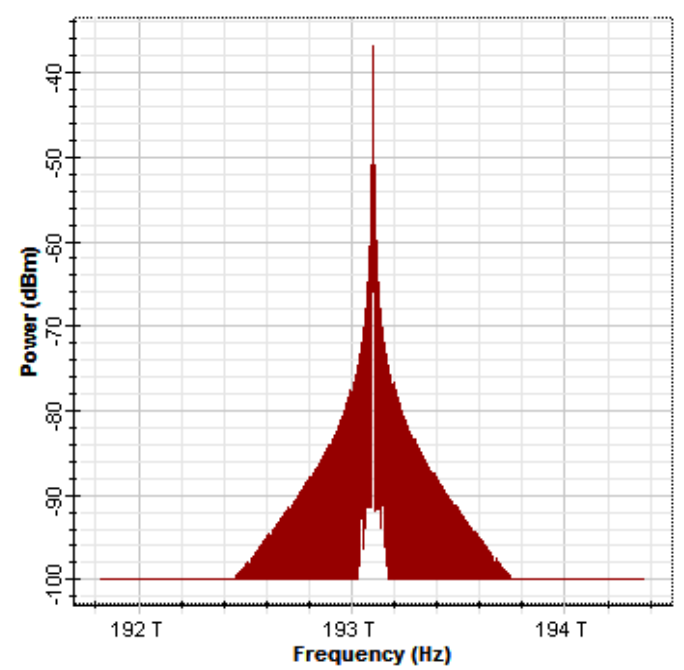

Figure 7. Optical Spectrum of Re-modulated OOK

Eye diagrams of downstream and upstream are shown in figure 8 and 9, open and wide eye has few errors in transmission but it is acceptable as BER and power of downstream and upstream are $3.41961 \times 10^{-046}$ and $4.10171 \times 10^{-018}$ and $-8.168 \mathrm{~dB}$ and $-34.347 \mathrm{~dB}$ respectively which is quite better as the power at standard receiver sensitivity BER i.e. $1 \times 10^{-9}$ is $-32.5 \mathrm{~dB}$ at downstream and $-42.5 \mathrm{~dB}$ at upstream. It can also be seen that the loss margin (i.e. receiver power without attenuator $3.41961 \times 10^{-046}$ minus standard receiver power sensitivity $1 \times 10^{-9}$ ) of the proposed system at downstream and upstream is $22.832 \mathrm{~dB}$ and $8.153 \mathrm{~dB}$ which is feasible and efficient for high data rate passive optical network. Figure 10 and 11 shows the simulation results obtained on back to back and $10 \mathrm{Km}$ fiber length DQPSK downstream and OOK upstream. Transmission power penalty for DQPSK downstream at $1 \times 10^{-9}$ i.e. standard Bit Error Rate (BER) is $1 \mathrm{~dB}$ only whereas for $\mathrm{OOK}$ is $0.5 \mathrm{~dB}$.

From the results, it can be seen that the proposed system is feasible and efficient for high data rate NG-PON.

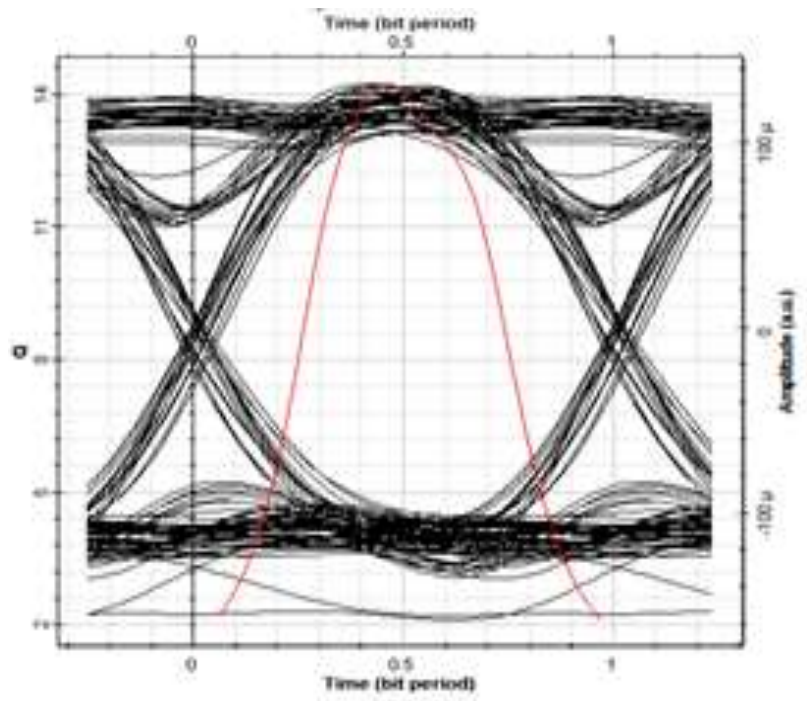

Figure 8. Eye Diagram of Downstream DQPSK Signal 


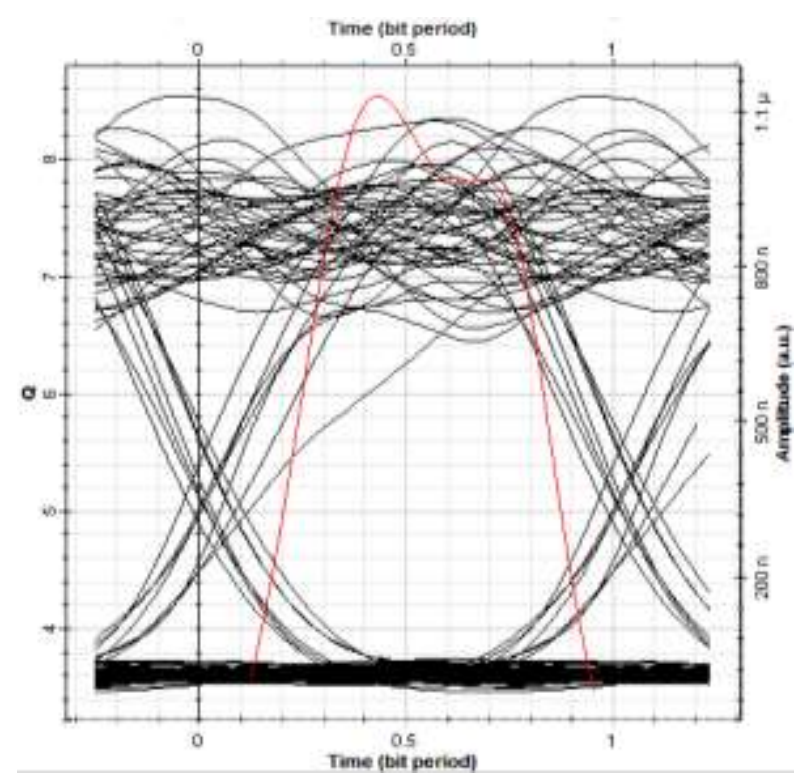

Figure 9. Eye Diagram of Upstream OOK Signal

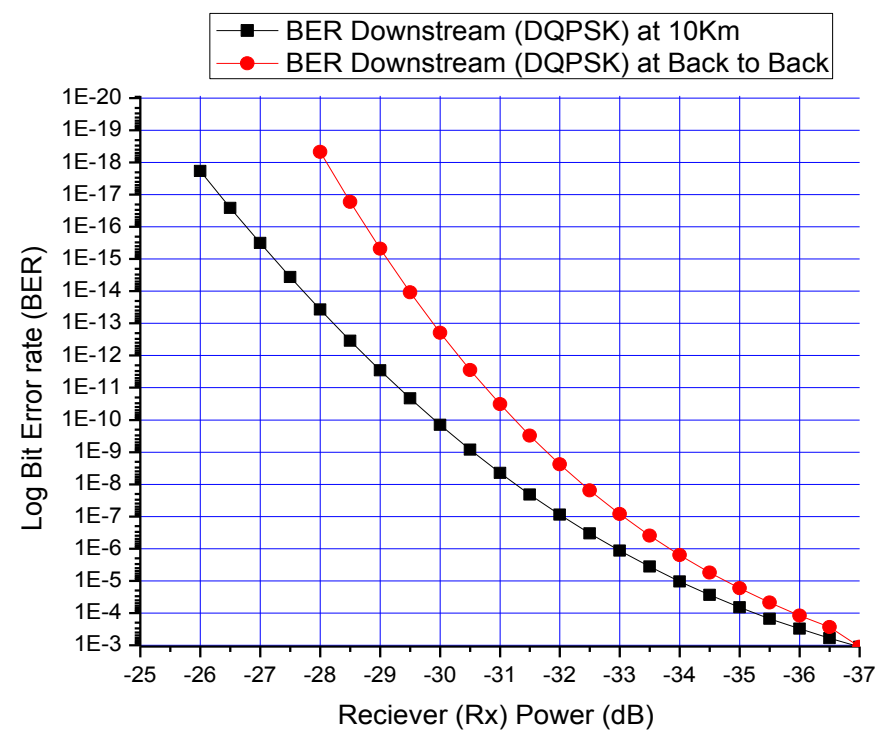

Figure 10. Rx Power vs BER 


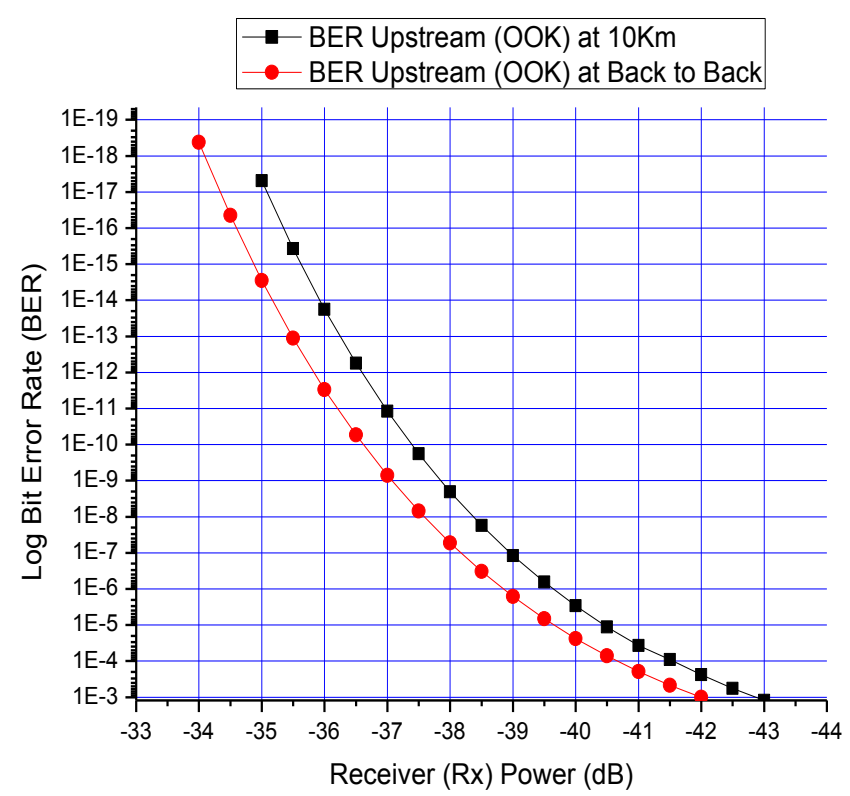

Figure 11. Rx Power vs BER

\section{Conclusion}

In the proposed setup, 40Gbps DQPSK modulated downstream and 10Gbps OOK modulated upstream have been investigated. The simulation results of the proposed scheme validate that data transmission for $10 \mathrm{~km}$ fiber span has been successfully achieved with very low transmission power penalties in both directions. Therefore it is recommended as a viable solution to cope up the high data rate demand of NG-PON 2.

\section{References}

[1] D. Nesset, "PON Roadmap [Invited]", Journal of Optical Communications and Networking, vol. 9, no. 1, (2017), A71-A76.

[2] H. S. Abbas and M. A. Gregory, "The next generation of passive optical networks: A review", Journal of Network and Computer Applications, vol. 67, (2016), pp. 53-74

[3] J. L. Wei, K. Grobe and H. Griesser, "High speed next generation passive optical networks: performance, cost, and power dissipation", Progress in Electromagnetic Research Symposium (PIERS). IEEE, (2016).

[4] D. Nesset, "NG-PON2 Technology and Standards", J. Lightwave Technol, vol. 33, (2015), pp. 11361143.

[5] H. Nakamura, "NG-PON2 Technology", Optical Fiber Communication Conference/National Fiber Optic Engineers Conference 2013, OSA Technical Digest (online) (Optical Society of America, 2013), paper NTh4F.5

[6] T. Tokle, et al. "Advanced modulation formats for transmission systems", Optical Fiber communication /National Fiber Optic Engineers Conference, 2008. OFC/NFOEC 2008. Conference on. IEEE, (2008).

[7] A. N. Z. Rashed, et al., "Performance Improvement for 16× 40 Gb/s DWDM System Using Non Return to Zero (NRZ), Return-to Zero (RZ) and Modified Duo Binary RZ (MD-RZ) Modulation Formats." International Journal of Advanced Research in Computer Science and Electronics Engineering (IJARCSEE), vol. 6, no. 2, (2017), pp. 11.

[8] M. B. U. Kamalpreet, "Performance Analysis of CSRZ, MDRZ, NRZ and DPSK Modulation Formats for Two Channel WDM Passive Optical Network", International Journal of Engineering and Applied Sciences (IJEAS) vol. 2, no. 5, (2015).

[9] A. K. Garg and V. Janyani, "Analysis of OOK Upstream Signal Remodulation for Different Data Rates in WDM PON Network", (2015).

[10] T. U. Islam, A. Hussain and S. S. Ashraf. "10Gbps bidirectional transmission GPON network based on single fiber", Emerging Technologies (ICET), 2015 International Conference on. IEEE, (2015).

[11] J. Latal, et al. "Simulation of modulation formats for optical access network based on WDM-PON." Transparent Optical Networks (ICTON), 2014 16th International Conference on. IEEE, (2014). 
[12] A. Chenika, A. Temmar and O. Seddiki, "Transmission of $4 \times 40 / 10$ Gbps in a WDM-PON using NRZDQPSK/ASK modulation", Optik-International Journal for Light and Electron Optics, vol. 125, no. 20, (2014), pp. 6296-6298

[13] A. Chenika, A. Temmar and O. Seddiki, "A Novel architecture of an optical high-speed access network WDM-PON using NRZ-DQPSK/ASK modulation", ICNCRE'13, (2013), pp. 396-398

[14] A. M. Khan, et al., "A Cost-effective and Spectrally-efficient Design of Centralized Light Source WDM-PON using Aggregated $160 \mathrm{Gbit} / \mathrm{s}$ DQPSK Modulation for Downstream and Re-modulated IRZ for Upstream Transmission", Advances in Information Sciences and Service Sciences, vol. 5, no. 3, (2013), p. 305.

[15] A. M. Khan, et al., "A Simple and Cost-effective Design for Simultaneous Transmission of Point-topoint and Broadcast Services in WDM-PON", International Journal of Future Generation Communication and Networking, vol. 6, no. 3, (2013), pp. 41-56.

[16] U. Tiwari, et al., "Performance Analysis of UDWDM Passive Optical Network with Enhanced Span Length using FBG based Dispersion Compensation", International Conference on Fibre Optics and Photonics. Optical Society of America, (2016).

[17] M. K. Gupta, et al., "Performance Analysis and Optimization of 40 Gbps Transmission System over 4000 km with FBG", Proceedings of the International Conference on Recent Cognizance in Wireless Communication \& Image Processing. Springer India, (2016).

[18] R. Rajarajan and S. Prince, "FTTH architecture with FBG based OCDMA network", Communication and Signal Processing (ICCSP), 2016 International Conference, (2016).

[19] A. F. F.Cabete, "Optical Fiber Systems with Dispersion Compensation". 
International Journal of Future Generation Communication and Networking Vol.10, No.8 (2017) 